EESTI NSV TEADUSTE AKADEEMIA TOIMETISED. 21. KOIDE

KEEMIA * GEOLOOGIA. 1972, NR. 1

ИЗВЕСТИЯ АКАДЕМИИ НАУК ЭСТОНСКОИ ССР. ТОМ 21

Химия * ГЕОЛОГИя. 1972. № 1

удК $543.422 ; 549.753 .1 ; 661.632$

М. ВЕИДЕРМА, РЭНА КНУБОВЕЦ

\title{
ИССЛЕДОВАНИЕ ФОСФАТНОГО ВЕЩЕСТВА ОБОЛОВЫХ ФОСФОРИТОВ МЕТОДОМ ИНФРАКРАСНОЙ СПЕКТРОСКОПИИ
}

В настоящей статье приведены результаты исследования структурных особенностей фосфатного вешества фосфоритов Маардуского и Кингисеппского месторождений и его превращений при термической пере работке с использованием методов инфракрасной спектроскопии и рент генографии.

Исследование фосфатного вещества оболовых фосфоритов представ ляет значительный теоретический и практический интерес. Ранее для этого были применены методы химического, термического и кристаллооптического анализов, избирательного растворения и рентгенографии $\left[{ }^{1-7}\right]$ В настоящей работе с целью болєе подробного изучения его структурных особенностей использован метод инфракрасной спектроскопии.

В ИК-спектрах минералов в области до $20 \mu$ в основном проявляются внутренние колебания сложных анионов, связи внутри которых сильнее, чем между другими атомами в кристалле. В первом приближении сложные ионы в решетке кристалла можно рассматривать как отдельные молекулы, симметрия которых искажена влиянием решетки в целом Понижение симметрии иона в решетке приводит к полному или частичному снятию вырождения колебательных уровней, а также к появлению в спектре частот, запрещенных правилами отбора для симметричной конфигуращии иона.

На рис. 1 схематично изображено изменение числа полос в спектре при изменении симметрии аниона $\left(\mathrm{PO}_{4}\right)^{3-}$. Девять возможных колебаний этого аниона $\left.{ }^{8}\right]$ в случае равноценности всех четырех связей $\mathrm{P}-\mathrm{O}$, т. е. при тетраэдрической симметрии $T_{d}$, дают лишь две полосы спектра: асимметричное валентное колебание $v_{3}$ в области $1100 \mathrm{~cm}^{-1}$ и асимметричное деформационное колебание $v_{4}$ вблизи $600 \mathrm{~cm}^{-1}$, так как полносимметричное валентное колебание $v_{1}$ у $980 \mathrm{~cm}^{-1}$ и симметричное деформационное колебание $v_{2}$ вблизи $400 \mathrm{~cm}^{-1}$ запрещены. В случае равноценности трех связей из че тырех (симметрия $\mathrm{C}_{3 v}$ ) становятся активными колебания $v_{1}$ и $v_{2}$ и частично снимается вырождение трижды вырожденных колебаний $v_{3}$ и $v_{4}$. При неравноценности двух связей $\mathrm{P}-\mathrm{O}$ двум дру гим (точечная группа симметрии $\mathrm{C}_{2 v}$ ) вырождение колебаний $v_{3}$ и $v_{4}$ снимается полностью. Нако-

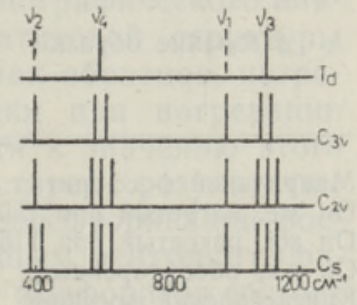

Рис. 1. Схематическое изображение изменения числа полос в ИК-спектре при снижении симметрии аниона $\left(\mathrm{PO}_{4}\right)^{3-}$. 


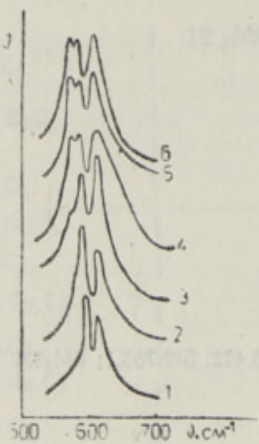

Рис. 2. Инфракрасные спектры природных фосфатов в области колебания $v_{4}$ аниона $\left(\mathrm{PO}_{4}\right)^{3-} .1$ - апатит, $2-$ подольский фосфорит, 3 - каратауский фосфорнт, 4 - маардуский фосфорит, 5 кингисеппский фосфорит, 6 - егорьевский фосфорит.

нец, в случае, когда все четыре связи различны (симметрия $\mathrm{C}_{s}$ ), появляется еше одно изменение в спектре - снятие вырождения дважды вырожденного колебания $v_{2}$.

Наиболее чувствительным к структурным особенностям природных фосфатов является асимметричное деформационное колебание фосфатного аниона.

В зависимости от полного или час-
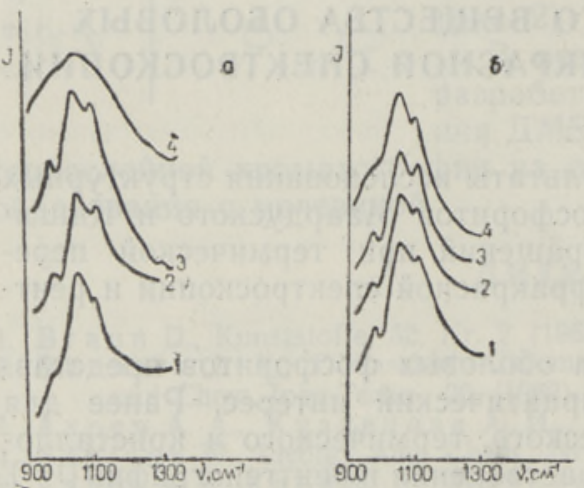

тичного снятия вырождения этого колебания фосфориты могут быть разделены на два различных типа [9]. ИК-спектры фосфатов показываIот * (рис. 2), что апатит и подольский фосфорит имеют две полосы колебания $v_{4}$ с частотами при 602 и $574 \mathrm{~cm}^{-1}$, а в спектре егорьевского н оболового фосфоритов имеются три полосы - при 602, 574 и $562 \mathrm{~cm}^{-1}$. Следовательно, оболовые фосфориты относятся к типу, для которого характерно полное снятие вырождения колебання $v_{4}$ аниона $\left(\mathrm{PO}_{4}\right)^{3-}$ и снижение симметрии фосфатного аниона до $\mathrm{C}_{2 v}$. В спектре каратауского фосфорита (месторождение Аксай) также различимы три полосы колебания $v_{4}$, но полоса при $562 \mathrm{~cm}^{-1}$ представлена лишь точкой пере-

гнба.

Рис. 3. Изменение колебаний $v_{1}$ и $v_{2}$ aниolia $\left(\mathrm{PO}_{4}\right)^{3-}$ маардуского $(a)$ II киннсеппского (б) фосфорнта при термиче ской переработке. 1 - исходный обра зец, 2 - образец, нагретый при $750^{5} \mathrm{C}$ 3 - то же, при $1150^{\circ}, 4$ - обесфторен. ный образец.

Следует отметить, что хотя относительная интенсивность полос колебания $v_{4}$ разных фосфоритов различна, полнсстью расшифровать эту структурную информацию в настоящее время не представляется возможным. По-видимому, в определенной мере эти различия вызваны

Данные химического и рентгенографического анализов фосфоритов

\begin{tabular}{|c|c|c|c|c|c|c|}
\hline \multirow[t]{2}{*}{ Название образца } & \multicolumn{4}{|c|}{ Содержание, \% } & \multicolumn{2}{|c|}{$\begin{array}{c}\text { Параметры крис } \\
\text { таллической } \\
\text { ячейки, } \AA\end{array}$} \\
\hline & $\mathrm{P}_{2} \mathrm{O}_{5}$ & $\mathrm{r}$ & $\mathrm{CO}_{2}$ фосф & $\mathrm{CO}_{2 \text { карб. }}$ & $a$ & $c$ \\
\hline Маардуский фосфорнт & 30,60 & 3,15 & 2,73 & 1,01 & 9,356 & 6,887 \\
\hline Он же, нагретый при $750^{\circ}$ & 31,60 & 2,98 & 2,30 & 0,09 & 9,363 & 6,887 \\
\hline Он же, нагретый при $1150^{\circ}$ & 32,55 & 2,09 & 0,05 & 0 & 9,373 & 6,884 \\
\hline Он же, обесфторенный & 33,12 & 0,20 & - & - & - & - \\
\hline Кингисеппский фосфорит & 27,80 & 2,81 & 3,57 & 2,66 & 9,353 & 6,887 \\
\hline Он же, нагретый при $750^{\circ}$ & 30,00 & 2,58 & 2,72 & 0,08 & 9,360 & 6,689 \\
\hline Он же, нагретый при $1150^{\circ}$ & 31,10 & 2,05 & 0,1 & 0 & 9,366 & 6,884 \\
\hline Он же, обесфторенный & 31,60 & 0,28 & - & 一 & - & - \\
\hline
\end{tabular}

* ИК-спектры снимались иа приборе ИК-20, образцы фосфатов готовнлись в виде суспензии в вазелиновом масле. 
разной степенью вхождения карбонатиона в структуру фторапатита. Как известно, по приблизительным кристаллохимическим формулам, в фосфатном веществе егорьевского фосфорита 1,2-1,4 атома фосфора (из шести в молекуле фторапатита) заменены углеродом, у оболовых фосфоритов - 0,7 атома, а у фосфорита Аксай эта замена не превышает 0,5 атома $[4,7,10]$.

Для определения изменений в колебаниях аниона $\left(\mathrm{PO}_{4}\right)^{3-}$ фосфатного минерала оболовых фосфоритов в ходе термической переработки были исследованы продукты их ғагревағня в атмосфере воздуха в течение 3 ч при 750 и $1150^{\circ} \mathrm{C}$, а также продукты их обесфторивания при 1250 - $1300^{\circ}$. Данные химического и рентгенографического анализов проб прнведены в таблице. Для того чтобы различить карбонатионы, входящие в состав фосфатного вещества и карбонатов (кальцита, доломпга), применен метод избирательного растворения [7, 11]. Для выполнения рент генографического анализа на медном излучении использовался дифрак тометр УРС-50 ИМ. По данным химического анализа, в образцах, на гретых до $750^{\circ}$, практически отсутствует $\mathrm{CO}_{2}$ карбонатов, а в образцах, нагретых до $1150^{\circ}$, также $\mathrm{CO}_{2}$, связанная с фосфатным веществом фос. форита.

ИК-спектры исходных фосфоритов и продуктов их нагревания и обесфторивания в области колебаний $v_{1}$ и $v_{3}$ фосфатного аниона мало отли чаются друг от друга (рис. 3) “и совпадают с приведенными в $\left[{ }^{12,13}\right.$ спєктрами.

Характерная особенность апатитов, как установлено ранее [14-16], - наличие водородной связи F...HO, направленной вдоль гексагональной оси кристалла. Спектральным признаком присутствия этой связи является появ. ление в спектре валентных колебаний гидрсксильных групп с частотой $3540 \mathrm{~cm}^{-1}$ и наличие либрационных колебаний ОН-групп около $670 \mathrm{~cm}^{-1}$. Названные полосы поглощения обнаружены в ИК-спектрах оболовых фос-
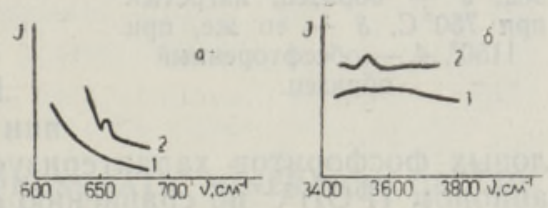

Рис. 4. Изменение ИК-спектров обо ловых фосфоритов при нагреванин $a$ - в области либрационных, б валентных колебаний ОН-групп. 1 исходный образец, 2 - образец, на гретый при $1150^{\circ} \mathrm{C}$. форитов, нагретых при $1150^{\circ}$ (рис. 4)

В спектрах исходных образцов фосфоритов установить эти полосы погло-

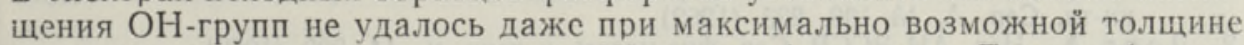
слоя образца и увеличении щели ИК-спектрофотометра. Таким образом, подтвердилось ранее сделанное предположение [3] о переходе фосфатного вещества оболовых фосфоритов (фторкарбонатапатита) во фторапатит нагреванием при $1050-1200^{\circ}$. По результатам рентгенографического анализа также установлено, что характерные для апатитовой структуры линии являются наиболее четкими в дифрактограммах образцов, нагретых при $1150^{\circ}$. Параметр а кристаллической ячейки при нагреванин обслового фосфорита увеличивается и приближается к значенню этого показателя у фторапатита $(9,38)$, что соответствует результатам работ по исследованию других фосфатов [ $\left.{ }^{17-19}\right]$. При обесфторивании фос форитов апатитовая структура разрушается. По данным рентгенографического анализа, обесфторенный фосфат из оболовых фосфоритов состоит в основном из $\beta-\mathrm{Ca}_{3}\left(\mathrm{PO}_{4}\right)_{2}$ и $\mathrm{Ca}_{4} \mathrm{P}_{2} \mathrm{O}_{9}$.

Наконец, представляет интерес выяснение особенностей колебаний $\mathrm{CO}_{3}$-групп в исследуемых фосфоритах. Из сравнения НК-спектров кальцита, доломита и оболовых фосфоритов в области колебания $v_{3}$ аниона $\left(\mathrm{CO}_{3}\right)^{2-}$ следует, что в спектрах карбонатных минералов нмеется одна 


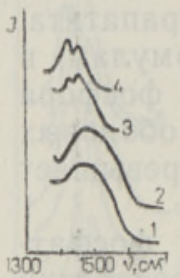

Рис. 5. ИК-спектры в области колебания $v_{3}$ аннона $\left(\mathrm{CO}_{3}\right)^{2-}, t-$ кальцит, 2 - доломит, 3 - кингисеппский фосфорит, 4 - маардуский фосфорит

полоса поглощения колебания $v_{3}$, а в спектре фосфоритов две полосы (рис. 5). Это позволяет предположить снижение симметрии аниона $\left(\mathrm{CO}_{3}\right)^{2-}$ в фосфоритах и говорит в поль-

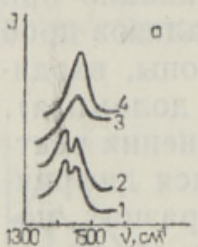

зу представления о вхождении карбонатиона в фосфатный минерал оболовых фосфоритов $\left[{ }^{1-7}\right]$. Две аналогичные полосы поглощения аниона $\left(\mathrm{CO}_{3}\right)^{2-}$ в спектре-природного фторкарбонатапатита (франколита) при 1460 и $1430 \mathrm{~cm}^{-1}$ обнаружены в $\left.{ }^{20-22}\right]$. По мере увеличения температуры нагревания фосфорита исчезает одна из полос в области колебаний карбонатиона (рис. 6). Причина сохранения второй полосы требует дальнейшего изуче-

Рис. 6. Изменение ИК-спектров в области колебания $v_{3}$ аниона $\left(\mathrm{CO}_{3}\right)^{2-}$ маардуского (a) и кингисеппского (б) фос форита при термической переработке. 1 - исходный образец, 2 - образец, нагретый при $750^{\circ} \mathrm{C}, 3-$ то же, при

$1150^{\circ}, 4$ - обесфторенный образец. ния. Не исключено, что в эту область попали полосы поглощения иных колебаний, например, деформационных колебаний гидроксильных групп.

\section{Выводы}

1. Методом инфракрасной спектроскопии показано, что фосфатное вещество оболовых фосфоритов характеризуется менее симметричным комплексным анионом $\left(\mathrm{PO}_{4}\right)^{3-}$ по сравнению с фторапатитом.

2. Установлено, что при нагревании до $1150^{\circ}$ в фосфатном веществе оболовых фосфоритов образуется характерная для апатита водородная связь F ...НО. Обесфторивание фосфоритов при более высоких темпе ратурах ведет к разрушению апатитовой структуры.

\section{Л И ТЕ Р А Т У $\mathrm{P}$ A}

1. Вейдерм а М. А., Ансо Я. Я., Қ асесалу С. П., Тр. Таллинск. политехн. ин-та, Сер. А, № 198, 233 (1962).

2. Л о о Г А., Изв. АН ЭССР, Сер. физ-матем. и техн. н., 11, 229 (1962).

3. В ейд е рм а М. А., Тр. Таллинск. политехн. ин-та, Сер. А, № 210, 315 (1964)

4. С мирнов А. И., В кн.: Физические методы исследования минералов осадочных пород, М., 1966 , с. 260.

5. В ейд е рм а М. А., В ески м яэ Х. И., Тр. научно-гехн. конфер. Оболовые фосфоригы как сырье для химической промышленности, Таллин, 1968, с. 19.

6. С м н рн в А. И., Промышленность горнохимического сырья и природных солей. № 2,7 (1969).

7. Вейдер м а М., Вески м яэ Х., Изв. АН ЭССР, Хим. Геол., 20, 8 (1971)

8. Г ерц б ерг Г., Қолебательные и вращательныс спектры многоатомных молекул, M., 1949.

9. Кн убов ец Р. Г., Автореф. канд. дисс., М., 1970.

10. С м и нов А. И., Платов а М. Н, Промышленность горнохимического сырья и природных солей, № 1, 5 (1970).

11. Silverma n S. R., Fuy at R. K., We iser I. D., Am. Mineralogist, 37, 211 (1952).

12. Печковский В. В., Тетеревков А. И., Мельникова Р. Я. и др., ЖПХ, 43, $482(1970)$.

13. Вей де р м а М. А., В ески м яэ Х. И., Материалы научно-техн. конфер. по проблемам фосфора и его пройзводных, Л., 1971 , с. 158.

14. Knoubovets R. G., A f a n a s jev M. L., H a buda S. P., Spectroscopy letters, 2, No. $5,12(1969)$.

15. Қнубовец Р. Г., Смирнов А. И., Кристаллография, 15, 477 (1970). 
16. Кисловский Л. Д., Кнубовец Р. Г., Зап. Всесоюзн. минерал. об-ва, 99, 609 (1970).

17. Ка виц ка я Ф. А., Тр. ГИГХС, № 7,280 (1962).

18. Смирнов А. И., Ивницкая Р. Б., Плотникова В. И., Фридман Н.Г., Тр. ГИГХС, № 4, 5 (1958).

19. A n d o J., Mat s u no S., Bull. Chem. Soc. Japan, 39, 1915 (1966).

20. B on el G., Monte I G., C. R. Acad. Sci. (Paris), 258, 923 (1964).

21. Legeros R. Z., Trautz O. R., Legeros J. P., Klein E., Bull. Soc. Chim France, $\mathrm{N}^{\circ} 4,1712(1968)$.

22. W in a nd L., Bull. Soc. Chim. France, $n^{\circ} 4,1718$ (1968).
Таллинский политехнический институт
Научно-исследовательский институт
Поступила в редакцию горнохимического сырья

M. VEIDERMA, RENA KNUBOVETS

\section{OOBOLUSFOSFORIIDI FOSFAATSE AINE UURIMINE INFRAPUNASE SPEKTROSKOOPIA MEETODIL}

Esitatakse andmed oobolusfosforiidi fosfaatse aine struktuuri ja selle muutumise kohta termilisel töötlemisel, kasutades infrapunast spektroskoopiat ja röntgenograafiat. Tehti kindlaks, et oobolusfosforiit erineb apatiidist fosfaatiooni madalama sümmeetria poolest. Fosforiidi kuumutamisel kuni $1150^{\circ} \mathrm{C}$ tekib vesinikside ning fosforiit läheneb struktuurilt apatiidile. Kōrgematel temperatuuridel ärastub fosforiidist fluor ja apatiidi struktuur laguneb

\section{VEIDERMA, RENA KNOUBOVETS}

\section{AN INFRARED SPECTROSCOPIC STUDY OF PHOSPHATIC MINERAL IN OBOLID PHOSPHORITE}

The authors present results of a study of the structure of phosphatic mineral in obolid phosphorite and its changes at thermal treatment. Obolid phosphorite differs from apatite by a lesser symmetry of phosphate ion. When heating the obolid phosphorite up to $1150^{\circ} \mathrm{C}$, a hydrogen bond is formed, and the structure of the obolid phosphorite becomes similar to that of apatite. At higher temperature the obolid phosphorite is defluorinated and the apatite structure is destroyed 